\title{
Preparation of Titania Nanoparticles with Tunable Anisotropy and Branched Structures from Core-Shell Molecular Bottlebrushes
}

Guojun Xie ${ }^{a}$, Hangjun Ding ${ }^{a}$, William Daniel ${ }^{b}$, Zongyu Wang ${ }^{a}$, Joanna Pietrasik ${ }^{c}$, Sergei S. Sheiko ${ }^{\mathrm{b}}$, Krzysztof Matyjaszewski ${ }^{\mathrm{a}, \mathrm{c}^{*}}$.

a Department of Chemistry, Carnegie Mellon University, 4400 Fifth Avenue, Pittsburgh, PA 15213, USA

${ }^{b}$ Department of Chemistry, University of North Carolina at Chapel Hill, Chapel Hill, NC 27599-3290, USA

c Institute of Polymer and Dye Technology, Lodz University of Technology, Stefanowskiego 12/16, 90-924 Lodz, Poland

${ }^{*}$ Corresponding author.

E-mail address: km3b@andrew.cmu.edu

\begin{abstract}
Core-shell molecular bottlebrushes with various topologies and with poly(tert-butyl acrylate)- $b$-polystyrene (PtBA-b-PS) block copolymer side chains were synthesized via atom transfer radical polymerization (ATRP). After hydrolysis of the PtBA segments and their conversion to poly(acrylic acid) (PAA), the materials were used as templates to prepare titania nanoparticles. Transmission electron microscopy (TEM) images showed that the particles retained the characteristic shape of the templates, including branches and cylindrical geometry. The cylindrical dimensions, i.e. diameter and length, were controlled by the number average degrees of polymerization of the PAA side-chain block and the polymethacrylate backbone, respectively. Thermogravimetric analysis (TGA) showed the weight fraction of inorganic content ranged from $17 \%$ to $35 \%$, depending on the ratio of the length of PAA and PS blocks.
\end{abstract}

KEYWORDS: molecular bottlebrushes; templates; nanoparticles 


\section{Introduction}

Molecular bottlebrushes are macromolecules containing long polymeric backbones with densely grafted polymeric side chains [1-3]. Owing to their unique architecture, molecular bottlebrushes exhibit distinct properties suggesting many potential applications including photonics [4-7], lubricants [8], stimuli-responsive materials [9-13], supersoft elastomers [14-17], porous materials [18, 19], and drug delivery systems [20]. Molecular bottlebrushes can be synthesized via three strategies: "grafting through" $[4,21]$, "grafting to" [22-24], and "grafting from" [25-27]. Development of reversible deactivation radical polymerization (RDRP) or controlled radical polymerization (CRP) procedures, including atom transfer radical (ATRP) [28, 29], reversible addition-fragmentation chain transfer (RAFT) [30-33], and nitroxide-mediated polymerizations (NMP) [34] provided versatile routes for preparation of polymer brushes with controlled composition, molecular weight and dispersity of either or both backbones and side chains [35-46].

Although formally single molecules, molecular bottlebrushes have dimensions similar to some self-assembled nano-objects such as polymer micelles. Due to strong steric repulsion between the densely grafted side chains, the bottlebrushes adopt extended, cylindrical conformations if the length of the backbone is significantly longer than that of the side chains. This allows molecular bottlebrushes with block copolymer side chains to be used as single-molecule templates for fabricating one-dimensional (1D) nanostructures such as nanowires and nanotubes [47-60]. Although sharing similar structures with micelles afforded by reversible self-assembly, molecular bottlebrushes do not undergo disassociation when the external environment is changed [61], offering unique opportunities for complexation and templating. Specific side chains can be incorporated to provide preferential affinities towards inorganic precursors. Therefore, composite materials with anisotropically arranged inorganic content could be selectively formed within these blocks, affording layered structures in the radial orientation. In this way, nanowires and nanotubes could be prepared using core-shell brush templates with the boundary of a nano-reactor defined by the core and the shell, respectively.

Due to their unique geometry and size-dependent optical, electronic, magnetic properties, 1D nanostructures are candidates for potential applications in the field of nanoelectronics, 
sensors, catalysis, energy harvesting, storage, and conversion [62-64]. Synthesis of branched inorganic nanostructures is an important research direction, which can generate hierarchical nanostructured networks with enhanced interconnectivity and percolation of nanoparticles $[65,66]$. For example, branched nanosized tetrapods offer the potential for charge transport in all spatial directions independent of their orientations [67, 68].

This paper presents procedures for the synthesis of anisotropic titania hybrid nanocomposites. Molecular bottlebrushes with poly(acrylic acid)-block-polystyrene (PAA- $b$-PS) side chains were synthesized via "grafting-from" methods and used as templates to prepare hybrid nanocomposites. The PS segments not only define the boundaries of PAA (then titania) cores but also serve as shells outside titania nano-objects preventing crosslinking, aggregation and enhancing processability [69]. The synthetic strategy of "grafting-from" allows systematic tuning of the lengths and topologies of brushes during the preparation of backbones via ATRP [42, 70, 71]. Structural features of templates such as anisotropy and morphology of the branches were effectively transferred into hybrid nanocomposites. Isotropic nanoparticles were also prepared from star-like templates [72-78].

\section{Experimental}

\subsection{Materials}

(2-Trimetylsiloxy)ethyl methacrylate (HEMA-TMS, Scientific Polymer Products), tertbutyl acrylate ( $t \mathrm{BA}, 99 \%$, Acros) and styrene (S, 99\%, Aldrich) were purified by passing the monomer through a column filled with basic alumina to remove the inhibitor. Pentaerythritol tetrakis(2-bromoisobutyrate) (4f-BiB) was synthesized according to procedures reported in the literature. [79]. Ethyl 2-bromoisobutyrate (EBiB, 98\%, Acros), copper(I) bromide $\left(\mathrm{Cu}^{\mathrm{I}} \mathrm{Br}, 99.999 \%\right.$, Aldrich), copper(I) chloride $\left(\mathrm{Cu}^{\mathrm{I}} \mathrm{Cl}, \geq 99.995 \%\right.$, Aldrich), copper(II) bromide $\left(\mathrm{Cu}^{\mathrm{II}} \mathrm{Br}_{2}, 98 \%\right.$, Acros $)$, copper(II) chloride $\left(\mathrm{Cu}^{\mathrm{II}} \mathrm{Cl}_{2}\right.$,

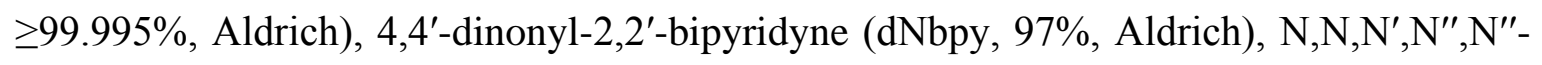
pentamethyldiethylenetriamine (PMDETA, 99\%, Aldrich), potassium fluoride (KF, 99\%, Aldrich), tetrabutylammonium fluoride (TBAF, $1.0 \mathrm{M}$ in THF, Aldrich), $\alpha-$ 
bromoisobutyryl bromide (98\%, Aldrich), 2,5-di-tert-butylphenol (DTBP, 99\%), triethylamine (TEA, $\geq 99 \%$, Aldrich), trifluoroacetic acid (TFA, $\geq 98 \%$, Aldrich), titanium(IV) 2-ethylhexanoate ( $\mathrm{Ti}(\mathrm{EH})_{4}, 97 \%$, Alfa Aesar) and solvents were used as received without further purification.

\subsection{Synthesis}

\subsubsection{Synthesis of PBiBEM (Backbone macroinitiator)}

The general procedure is described below for the synthesis of PBiBEM$_{56}$. A $25 \mathrm{~mL}$ Schlenk flask was charged with EBiB (67.2 mg, $0.345 \mathrm{mmol})$, HEMA-TMS (15.0 mL, $68.9 \mathrm{mmol})$, dNbpy (0.169 g, $0.414 \mathrm{mmol}), \mathrm{Cu}^{\mathrm{II}} \mathrm{Cl}_{2}(12.9 \mathrm{mg}, 0.0965 \mathrm{mmol})$, and anisole $(1.7 \mathrm{~mL})$. The solution was degassed by three freeze-pump-thaw cycles. During the final cycle, the flask was filled with nitrogen, and $\mathrm{Cu}^{\mathrm{I}} \mathrm{Cl}(10.9 \mathrm{mg}, 0.110 \mathrm{mmol})$ was quickly added to the frozen reaction mixture. The flask was sealed, evacuated, and backfilled with nitrogen five times and then immersed in an oil bath at $60{ }^{\circ} \mathrm{C}$. Polymerization was stopped when conversion reached $28.1 \%$ as determined by ${ }^{1} \mathrm{H}$ NMR spectroscopy. From the molar ratio of the reacted monomer to initiator, the degree of polymerization (DP) was calculated to be 56. The reaction mixture was diluted with methylene chloride, passed through neutral alumina column to remove the catalyst, then concentrated, and used in the next step without further purification.

A $50 \mathrm{ml}$ round-bottom flask was charged with the product of last step $(3.10 \mathrm{~g}, 15.4 \mathrm{mmol}$ HEMA-TMS), KF (1.09 g, $26.1 \mathrm{mmol})$, DTBP $(0.316 \mathrm{~g}, 1.53 \mathrm{mmol})$, and then dry THF $(30 \mathrm{~mL})$ was added under nitrogen. The reaction mixture was cooled down in an ice bath, followed by the injection of tetrabutylammonium fluoride $(0.15 \mathrm{~mL}, 1.0 \mathrm{M}$ in THF, 0.15 $\mathrm{mmol})$ and subsequent dropwise addition of $\alpha$-bromoisobutyryl bromide $(4.2 \mathrm{~g}, 2.3 \mathrm{~mL}$. $18.4 \mathrm{mmol}$ ) over the course of $20 \mathrm{~min}$. The reaction mixture was then allowed to reach room temperature and was stirred for another $24 \mathrm{~h}$. Afterwards the solids were filtered off and the mixture was precipitated by addition of the filtered solution to methanol/water (70/30), the solids were re-dissolved in methylene chloride $(20 \mathrm{~mL})$ and passed through the column filled with basic alumina. The product was re-precipitated three times in hexanes and dried overnight under vacuum. Apparent molecular weight determined by THF GPC: $\mathrm{M}_{\mathrm{n}, \mathrm{GPC}}=15,600$, and $\mathrm{M}_{\mathrm{w}} / \mathrm{M}_{\mathrm{n}}=1.19$. 
Three additional PBiBEM macroinitiators were prepared according to the above procedure using the stoichiometric ratios shown in Table 1.

Table 1. Experimental condition for the synthesis of PBiBEM ${ }^{\mathrm{a}}$

\begin{tabular}{cccccccccc}
\hline Entry & $\mathrm{M}$ & $\mathrm{dNbpy}$ & $\mathrm{CuX}^{\mathrm{b}}$ & $\mathrm{CuX}_{2}{ }^{\mathrm{b}}$ & solvent & $\mathrm{Conv}^{\mathrm{c}}$ & $\mathrm{DP}^{\mathrm{c}}$ & $\mathrm{M}_{\mathrm{n}}{ }^{\mathrm{d}}$ & $\mathrm{M}_{\mathrm{w}} / \mathrm{M}_{\mathrm{n}}{ }^{\mathrm{d}}$ \\
\hline $\mathbf{L}_{\mathbf{5 6}}$ & 200 & 1.2 & 0.32 & 0.28 & $10 \%$ & $28.2 \%$ & 56 & 15,600 & 1.19 \\
$\mathbf{L}_{\mathbf{2 0 2}}$ & 800 & 2.4 & 0.84 & 0.36 & $10 \%$ & $25.3 \%$ & 202 & 36,000 & 1.12 \\
$\mathbf{L}_{\mathbf{3 7 2}}$ & 1000 & 4.0 & 1.78 & 0.22 & $20 \%$ & $37.2 \%$ & 372 & 47,300 & 1.16 \\
$\mathbf{B}_{\mathbf{2 0 5}}{ }^{\mathbf{b}}$ & 4000 & 12 & 4.5 & 1.5 & $10 \%$ & $20.5 \%$ & $205^{\mathrm{e}}$ & 102,000 & 1.13
\end{tabular}

${ }^{a}$ Numbers in the column of $\mathrm{M}, \mathrm{dNbpy}, \mathrm{CuX}$ and $\mathrm{CuX}_{2}$ stand for relative ratios of initial monomer, ligand, $\mathrm{CuX}$ and $\mathrm{CuX}_{2}$ to initiator (initiator $=\mathrm{EBiB}$ for $\mathrm{L}_{56}, \mathrm{~L}_{202}$ and $\mathrm{L}_{372}$; initiator $=4 \mathrm{f}-\mathrm{BiB}$ for $\mathrm{B}_{205}$ ) concentrations, respectively; ${ }^{\mathrm{b}} \mathrm{X}=\mathrm{Cl}$ for $\mathrm{L}_{56}, \mathrm{~L}_{202}$ and $\mathrm{L}_{372} ; \mathrm{X}=\mathrm{Br}$ for $\mathrm{B}_{205} ;{ }^{\mathrm{c}}$ Conversion based on the monomer to initiator ratio and the conversion of HEMA-TMS measured by ${ }^{1} \mathrm{H}$ NMR; ${ }^{\mathrm{d}}$ Determined by SEC using linear PMMA standards. ${ }^{\mathrm{e}}$ Averaged DP of repeat unit at each arm.

\subsubsection{Synthesis of PBiBEM-g-(PtBA-b-PS)}

The general procedure for the synthesis of the bottlebrush macromolecules is described below for the synthesis of $\mathrm{L}_{56} \mathrm{~A}_{51} \mathrm{~S}_{73}$ (Table 2). A $100 \mathrm{~mL}$ Schlenk flask was charged with PBiBEM$_{56}(0.191 \mathrm{~g}, 0.684 \mathrm{mmol}$ initiator centers $), t \mathrm{BA}(50.0 \mathrm{~mL}, 342 \mathrm{mmol})$, dNbpy (0.349 g, $0.855 \mathrm{mmol}), \mathrm{Cu}^{\mathrm{II}} \mathrm{Br}_{2}(2.4 \mathrm{mg}, 0.85 \mathrm{mmol})$, and anisole $(5.6 \mathrm{~mL})$. The solution was degassed by three freeze-pump-thaw cycles. During the final cycle, the flask was filled with nitrogen, and $\mathrm{Cu}^{\mathrm{I}} \mathrm{Br}(59.6 \mathrm{mg}, 0.417 \mathrm{mmol})$ was quickly added to the frozen reaction mixture. The flask was sealed, evacuated, and backfilled with nitrogen five times and then immersed in an oil bath at $70{ }^{\circ} \mathrm{C}$. Polymerization was stopped when conversion reached $10.8 \%$ as determined by ${ }^{1} \mathrm{H}$ NMR spectroscopy. From the monomer conversion and the initial ratio of initiator to monomer the DP of tBA side chains was calculated to be 51 (assuming 100\% initiation efficiency from the multifunctional macroinitiator). Unreacted monomer was removed by ultrafiltration in MeOH/THF (50/50, vol\%) solution using an ultrafiltration membrane (Biotech, Regenerated Cellulose, MWCO: 3,500). The $\mathrm{P} t \mathrm{BA}$ brush was dried under vacuum to a constant mass.

The PtBA brush $(0.37 \mathrm{~g}, 0.0544 \mathrm{mmol}$ chain end, assuming $100 \%$ initiation efficiency in last step), styrene (5.0 mL, $44 \mathrm{mmol})$, PMDETA (10.4 mg, $0.0599 \mathrm{mmol}), \mathrm{Cu}^{\mathrm{II}} \mathrm{Br}_{2}(0.61$ 
$\mathrm{mg}, 0.0027 \mathrm{mmol})$, and anisole $(0.56 \mathrm{~mL})$ were added to a $10 \mathrm{~mL}$ Schlenk flask. The solution was degassed by three freeze-pump-thaw cycles. During the final cycle, the flask was filled with nitrogen, and $\mathrm{Cu}^{\mathrm{I}} \mathrm{Br}(7.4 \mathrm{mg}, 0.052 \mathrm{mmol})$ was quickly added to the frozen reaction mixture. The flask was sealed, evacuated, and backfilled with nitrogen five times and then immersed in an oil bath at $60{ }^{\circ} \mathrm{C}$. Polymerization was stopped when conversion reached $9.6 \%$ as determined by ${ }^{1} \mathrm{H}$ NMR spectroscopy. The reaction mixture was diluted with methylene chloride, passed through a neutral alumina column to remove the catalyst, concentrated, and the product precipitated by addition to methanol and dried overnight under vacuum. Apparent molecular weight determined by THF GPC: $\mathbf{M}_{\mathrm{n}, \mathrm{GPC}}=319,000$, and $\mathrm{M}_{\mathrm{w}} / \mathrm{M}_{\mathrm{n}}=1.30$.

The synthesis three other PBiBEM-g-(PtBA-b-PS) brushes $\left(\mathrm{L}_{202} \mathrm{~A}_{51} \mathrm{~S}_{105}, \mathrm{~L}_{372} \mathrm{~A}_{47} \mathrm{~S}_{92}\right.$, and $\mathrm{B}_{205} \mathrm{~A}_{53} \mathrm{~S}_{73}$ ) were conducted utilizing the above procedure (keeping stoichiometric ratios constant). Structural parameters and apparent molecular weights were summarized in Table 2.

\subsubsection{Hydrolysis of PtBA-b-PS Brush polymers.}

General procedure: $2.0 \mathrm{~g}$ of one of the PtBA- $b$-PS polymers was dissolved in $20 \mathrm{~mL}$ DCM. While the solution was vigorously stirred, a 5-fold molar excess of trifluoroacetic acid (TFA) with respect to the ester group was added slowly to the reaction. The reaction mixture was stirred at room temperature for $48 \mathrm{~h}$. PAA- $b$-PS brushes were obtained as a white solid after precipitation by addition to hexane and removal of the solvent and residual acid under vacuum.

\subsubsection{Synthesis of inorganic/polymer nanocomposites employing the PAA-b-PS brush as a template.}

General procedure: $100 \mathrm{mg}$ of the PAA- $b$-PS brush was dissolved in $10 \mathrm{~mL}$ DMF followed by addition of appropriate amounts of the inorganic precursors $\left(\mathrm{Ti}(\mathrm{EH})_{4}\right)$ that were selectively incorporated into the inner PAA blocks. The molar fraction of AA units in the PAA blocks to precursors was set at 1:10 to ensure the complete loading of the soluble precursors into the PAA domains. The resulting solution was stirred at room temperature overnight then refluxed at $180{ }^{\circ} \mathrm{C}$ for $5 \mathrm{~h}$. A transparent $\mathrm{TiO}_{2} /$ brush DMF 
solution was obtained after removing the precipitates by centrifuging. A transparent $\mathrm{TiO}_{2} /$ brush DMF solution was obtained after removing the precipitates by centrifuging. The $\mathrm{TiO}_{2} /$ brushes were further purified by precipitation into methanol to remove any unreacted precursors $\left(\mathrm{Ti}(\mathrm{EH})_{4}\right)$.

\subsection{Characterization.}

Number-average molecular weights $\left(M_{n}\right)$ and MWDs were measured by size exclusion chromatography (SEC). The SEC was conducted with a Waters 515 pump and Waters 410 differential refractometer using PSS columns (Styrogel $10^{5}, 10^{3}, 10^{2} \AA$ ) with THF as eluent at $35{ }^{\circ} \mathrm{C}$ and at a flow rate of $1 \mathrm{~mL} \mathrm{~min}^{-1}$. Linear PMMA standards were used for calibration. Conversion was calculated from the decrease of the monomer peak area relative to the peak areas of the internal standards. In addition, Polymerization was monitored by ${ }^{1} \mathrm{H}$ NMR spectroscopy using a Bruker Advance $300 \mathrm{MHz}$ NMR spectroscope with $\mathrm{CDCl}_{3}$ as a solvent.

Transmission electron microscopy (TEM) was performed using a JEOL 2000 EX electron microscope operated at $200 \mathrm{kV}$. TEM samples were prepared by a drop casting method with $1 \mathrm{mg} / \mathrm{mL}$ toluene solution of $\mathrm{TiO}_{2} /$ brushes. This methods resulted in sparse monolayers of titania nano-rods ensuring high fidelity of particle size measurements. Length and width distributions of titania nanoparticles were generated by image analysis of TEM using in-house developed software. Ensembles of 300 molecules were analyzed to ensure low standard error of the mean in the length and width distributions.

The fraction of $\mathrm{TiO}_{2}$ content was measured by thermogravimetric analysis (TGA), TA Instrument 2950, and the data was analyzed with TA Universal Analysis. The heating procedure involved 4 steps: 1 ) samples were placed on a platinum pan and the temperature increased to $120{ }^{\circ} \mathrm{C}$ in air atmosphere; 2) samples were held at $120{ }^{\circ} \mathrm{C}$ for $10 \mathrm{mins}$; 3) then temperature was ramped up at a rate of $20{ }^{\circ} \mathrm{C} / \mathrm{min}$ to $800{ }^{\circ} \mathrm{C}$; 4) samples were held for 5 mins. The TGA plots were normalized to the total weight after holding samples at $120{ }^{\circ} \mathrm{C}$.

The XRD measurement was performed at $25{ }^{\circ} \mathrm{C}$ on a Panalytical XPERT-PRO diffractometer in reflection mode using $\mathrm{Cu} \mathrm{K} \alpha$ radiation. 


\section{Results and discussion}

The general synthetic procedure employed for the brush template is shown in Scheme 1. First, the PBiBEM macroinitiator was prepared by ATRP of HEMA-TMS followed by functionalization with $\alpha$-bromoisobutyryl bromide. Second, the diblock copolymer side chains were grown from the macroinitiator via sequential ATRP of tert-butyl acrylate and styrene to create brushes with a core-shell architecture. The hydrolysis of the PtBA core with TFA prepared brush templates with a core of functional, anchoring groups (carboxylic acid groups) for metal precursors in the inner layer of the core-shell structures.

The length of the backbones was systematically varied by changing polymerization conditions of HEMA-TMS, such as the initial monomer/ initiator molar ratio and the final conversion of monomers (Table 1). Also, the architecture of the backbone was readily controlled by using a structure of initiator (Scheme 1). Utilizing a mono-functional initiator $(\mathrm{EBiB})$, a linear backbone was prepared, while a branched backbone was synthesized using a tetra-functional initiator (4f-BiB). Information on the brush templates used in this study is summarized in Table 2. The DP of PAA block remained about 50 in all templates, while the DP of backbone in linear samples was increased from 56 to 372 . 


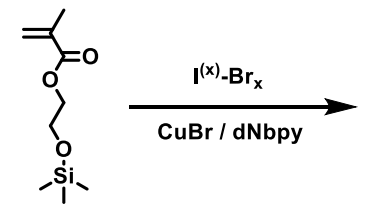

(HEMA-TMS)

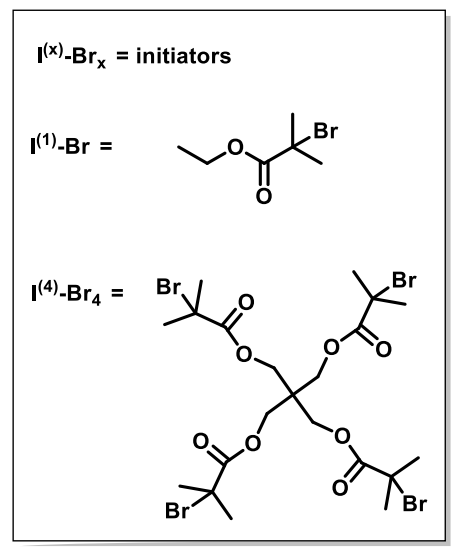

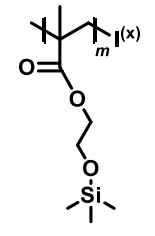

(PHEMA-TMS)
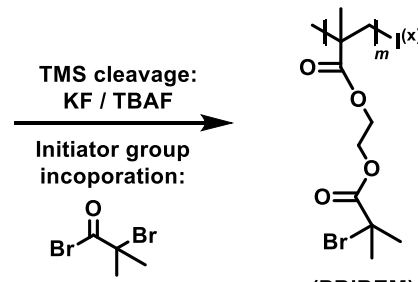

(PBiBEM)
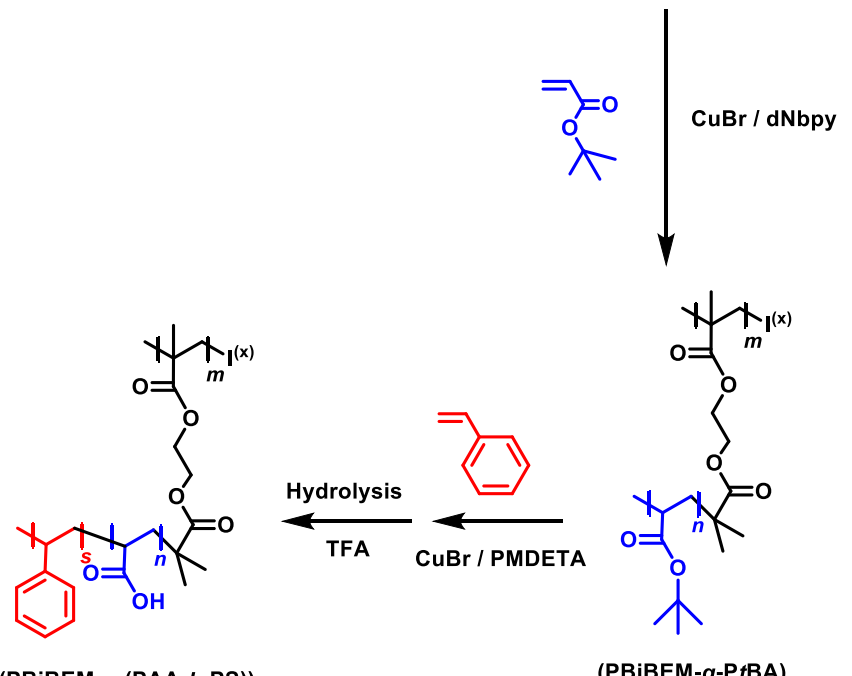

Scheme 1. Schematic illustration of the synthesis of brush templates.

Table 2. Structural parameters of templates

\begin{tabular}{|c|c|c|c|c|c|c|}
\hline \multirow{2}{*}{ Template ID ${ }^{\text {a }}$} & \multicolumn{3}{|c|}{ Parameters $^{b}$} & \multirow{2}{*}{$M_{n, \text { theory }}{ }^{d}$} & \multirow{2}{*}{$\mathbf{M}_{n, \mathbf{G P C}}{ }^{\mathrm{e}}$} & \multirow{2}{*}{$\boldsymbol{D}^{\mathrm{e}}$} \\
\hline & $\mathbf{D P}_{\text {Backbone }}$ & $\mathbf{D P}_{\mathbf{P A A}}$ & $\mathbf{D P}_{\mathbf{P S}}$ & & & \\
\hline $\mathbf{L}_{56} \mathbf{A}_{51} \mathbf{S}_{73}$ & 56 & 51 & 73 & 812,000 & 319,000 & 1.30 \\
\hline $\mathbf{L}_{202} \mathbf{A}_{51} \mathbf{S}_{105}$ & 202 & 51 & 105 & $3,570,000$ & 692,000 & 1.20 \\
\hline $\mathbf{L}_{372} \mathbf{A}_{47} \mathbf{S}_{92}$ & 372 & 47 & 92 & $5,900,000$ & 845,000 & 1.15 \\
\hline $\mathbf{B}_{205} \mathbf{A}_{53} \mathbf{S}_{73}$ & $205^{c}$ & 53 & 73 & $12,000,000$ & 951,000 & 1.52 \\
\hline
\end{tabular}

${ }^{\mathrm{a}} \mathrm{L}=$ linear, $\mathrm{B}=$ branched. $\quad{ }^{\mathrm{b}}$ Calculated based on the monomer to initiator ratio and conversion determined by ${ }^{\mathrm{I}} \mathrm{H}$ NMR in each step. ${ }^{\mathrm{c}}$ Averaged DP of repeat unit at each arm. ${ }^{\mathrm{d}}$ Calculated based on molecular parameters. ${ }^{\mathrm{e}}$ Determined by SEC using linear PMMA standards.

After loading with titanium (IV) 2-ethylhexanoate and refluxing at $180{ }^{\circ} \mathrm{C}$ in DMF, the nanostructures comprising titania nanoparticles were prepared. Transmission electron microscopy (TEM) images in Figure 1 clearly show the anisotropic structure of the 
inorganic-polymer hybrids and strong contrast not seen in naked polymer brushes, suggesting that the shape of the brush templates was preserved upon loading with the inorganic materials. For bottlebrushes with longer backbone ( $\mathrm{L}_{372} \mathrm{AA}_{47} \mathrm{~S}_{92}$ and $\mathrm{L}_{202} \mathrm{AA}_{51}$ $\mathrm{S}_{105}$ ), anisotropic nanoparticles with a worm-like structure were observed in the TEM images. Good control over both width and length was established by the statistical analysis of TEM images (Table 3). All particles showed the same diameters within the error (about $10 \mathrm{~nm}$ ) due to the similar DPs of PAA blocks, while the inorganic content was evenly distributed along the backbone, indicating the particles grew as solid inorganics with boundaries defined by the polystyrene segments rather than as clusters of individual particles. On the other hand, the length of nanoparticles increased from $55 \mathrm{~nm}$ to $77 \mathrm{~nm}$ as the DP of backbone in templates increase from 202 to 372 .

In contrast, the nanoparticles prepared using bottlebrushes with short backbone $\left(\mathrm{L}_{56} \mathrm{AA}_{51}\right.$ $\mathrm{S}_{73}$ ) showed mostly spherically-shaped structures in the TEM images (Figure 1C and $1 \mathrm{~F}$ ). Since the backbone has approximately the same length as the side chains, the entire macromolecular template adopts a star-like structure rather than a cylindrical shape (Scheme 2) [80, 81]. Some anisotropic particles could still be found, attributed to the length dispersity of the backbone. By comparing the length of nanoparticles afforded by different linear brush templates (Table 3, entry 1-3), the contribution to the length in each backbone could be estimated (assuming both ends as hemispheres and the rest parts as cylinders, Scheme 2): both ends contribute ca. $15 \mathrm{~nm}$ in total while each DPs of backbone gives $0.17 \mathrm{~nm}$. 


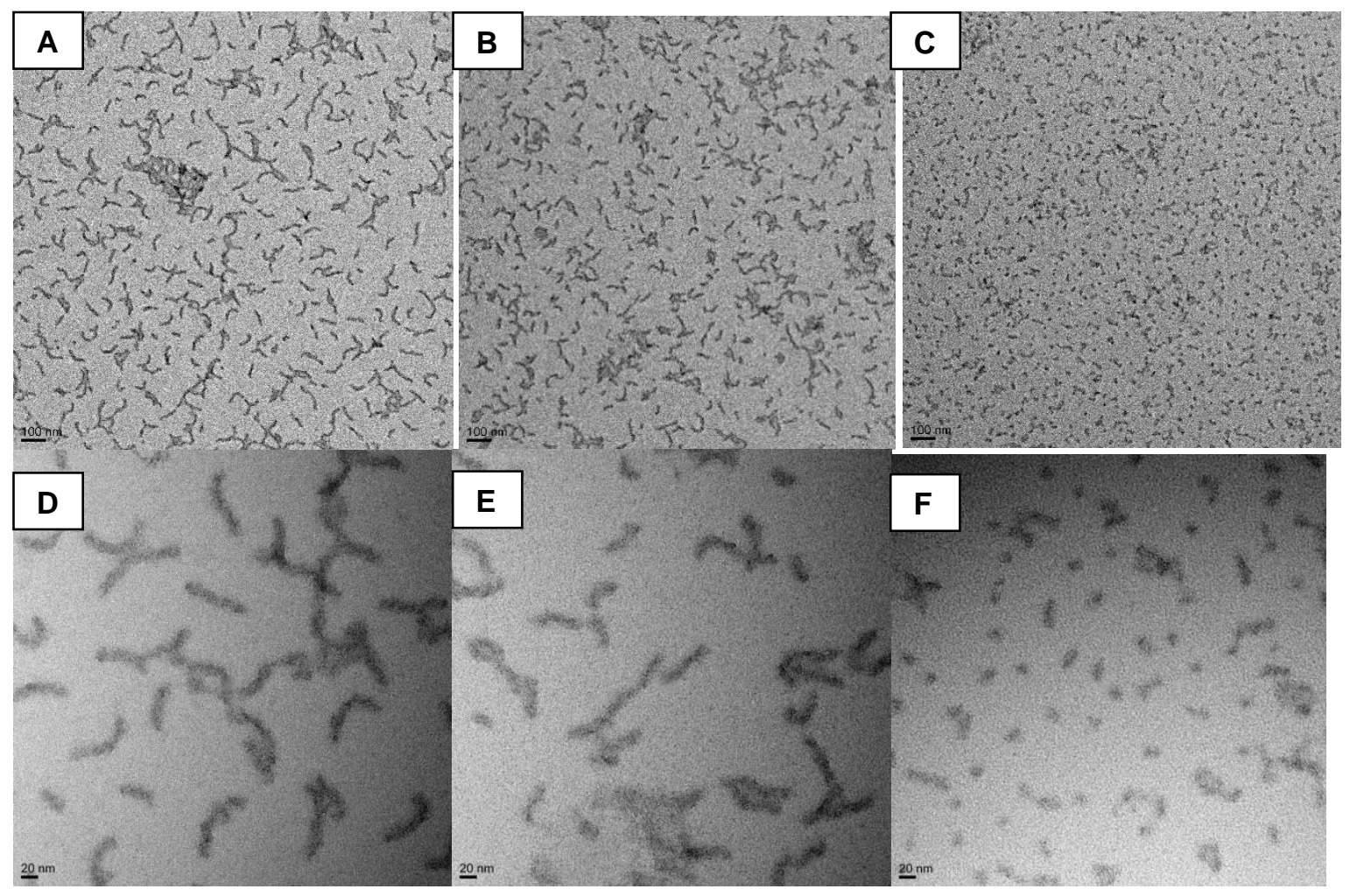

Figure 1.TEM images of titania nanoparticles prepared from templates of $\mathrm{L}_{372} \mathrm{AA}_{47} \mathrm{~S}_{92}(\mathrm{~A}$, D), $\mathrm{L}_{202} \mathrm{AA}_{51} \mathrm{~S}_{105}(\mathrm{~B}, \mathrm{E})$ and $\mathrm{L}_{56} \mathrm{AA}_{51} \mathrm{~S}_{73}(\mathrm{C}, \mathrm{F})$. Scale bar $=100 \mathrm{~nm}$ (in A, B, C) or 20 nm (in D, E, F).

Table 3. TEM characterization of the length $\left(\mathrm{L}_{\mathrm{n}}\right)$ and core diameter $\left(\mathrm{W}_{\mathrm{n}}\right)$ of titania hybrid nanoparticles prepared from templates with different backbones.

\begin{tabular}{|c|c|c|c|c|c|}
\hline entry & Template ID & $\boldsymbol{L}_{\boldsymbol{n}}(\mathbf{n m})$ & $\boldsymbol{L}_{w} / \boldsymbol{L}_{\boldsymbol{n}}{ }^{\mathbf{a}}$ & $\boldsymbol{W}_{\boldsymbol{n}}(\mathbf{n m})$ & $\boldsymbol{W}_{\boldsymbol{w}} / \boldsymbol{W}_{\boldsymbol{n}}{ }^{{ }^{a}}$ \\
\hline $\mathbf{1}$ & $\mathrm{L}_{56} \mathrm{~A}_{51} \mathrm{~S}_{73}$ & $21.8 \pm 0.4$ & 1.12 & $10.3 \pm 0.2$ & 1.05 \\
\hline $\mathbf{2}$ & $\mathrm{L}_{202} \mathrm{~A}_{51} \mathrm{~S}_{105}$ & $54.6 \pm 0.9$ & 1.13 & $10.7 \pm 0.2$ & 1.05 \\
\hline $\mathbf{3}$ & $\mathrm{L}_{372} \mathrm{~A}_{47} \mathrm{~S}_{92}$ & $77 \pm 1$ & 1.12 & $11.4 \pm 0.3$ & 1.04 \\
\hline $\mathbf{4}$ & $\mathrm{B}_{205} \mathrm{~A}_{53} \mathrm{~S}_{73}$ & $47.9 \pm 1.0^{\mathrm{b}}$ & 1.09 & $10.6 \pm 0.2$ & 1.04 \\
\hline
\end{tabular}

a Dispersity index of titania nanoparticles length or width obtained from TEM images. ${ }^{\mathbf{b}}$ Average length of a single arm. 


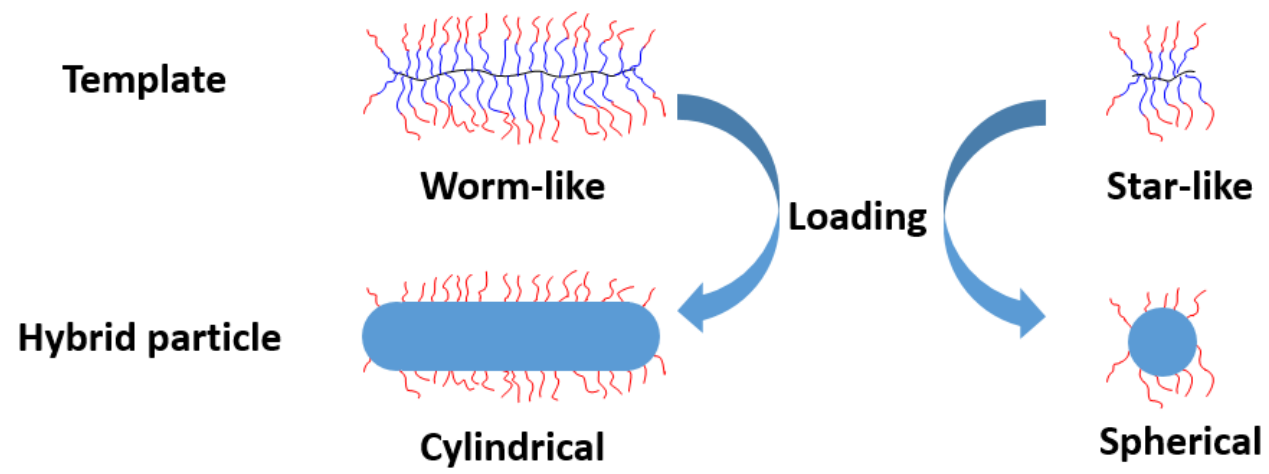

Scheme 2. Mechanism of the formation of anisotropic and isotropic hybrid particles.

In addition to the linear structures, nanoparticles with a branched architecture were prepared using bottlebrush templates with four arms (Figure 2). Although many four-arm nanoparticles could be observed, some two- and three-arm nanoparticles can also be found. It is possible that one arm in regular tetrapodal structures may not be visible in TEM images, if the fourth arm is perpendicular to the surface. According to statistical analysis (Table 3, entry 4), star-like nanoparticles have diameters $(\sim 10 \mathrm{~nm})$ similar to the linear nanoparticles in Figure 1, indicating that effective control over the width of nanoparticles by tuning the DPs of PAA blocks. 


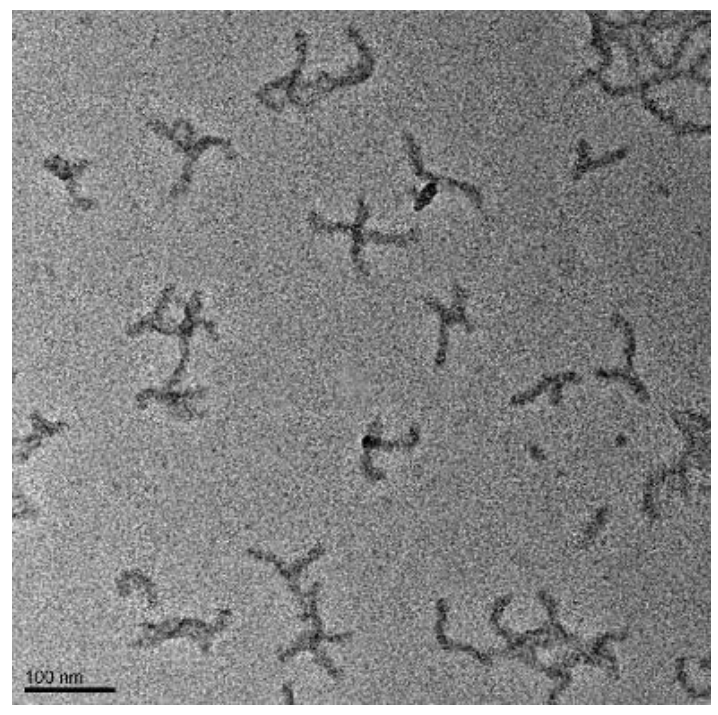

Figure 2. TEM images of $\mathrm{TiO}_{2}$-polymer hybrids prepared from the branched brush template $\mathrm{B}_{205} \mathrm{AA}_{53} \mathrm{~S}_{73}$. Scale bar $=100 \mathrm{~nm}$.

The weight fraction of the inorganic content was measured by thermogravimetric analysis (TGA). The weight fraction of inorganic content was higher than the value estimated by assuming that four acrylic acid groups bind one Ti atom (Table 4). This might be due to the nucleation and growth process in the nanoreactor during the formation of nanoparticle [72]. Another possible reason is that the formation of titania releases acrylic acid moieties which allow further incorporation of more metal precursors [51]. However, certain trends of inorganic content could be identified by comparison between nanoparticles prepared by different templates. The particles prepared using the templates with relatively longer PS chains as outer layers $\left(\mathrm{L}_{202} \mathrm{AA}_{51} \mathrm{~S}_{105}\right.$ and $\left.\mathrm{L}_{372} \mathrm{AA}_{47} \mathrm{~S}_{92}\right)$ have lower weight fraction of the inorganic content (Table 4, entry 2 and 3). The XRD measurements of the titania hybrid nanoparticles indicate amorphous material were achieved.

Table 4. TGA results of inorganic content of titania nanoparticles

\begin{tabular}{|c|c|c|c|}
\hline entry & Template ID & $\begin{array}{c}\text { Weight fraction of } \\
\text { inorganic content }^{\text {a }}\end{array}$ & $\begin{array}{c}\text { Calculated weight fraction } \\
\text { of inorganic content }\end{array}$ \\
\hline $\mathbf{1}$ & $\mathrm{L}_{56} \mathrm{AA}_{51} \mathrm{~S}_{73}$ & $35 \%$ & $8 \%$ \\
\hline $\mathbf{2}$ & $\mathrm{L}_{202} \mathrm{AA}_{51} \mathrm{~S}_{105}$ & $21 \%$ & $6 \%$ \\
\hline $\mathbf{3}$ & $\mathrm{L}_{372} \mathrm{AA}_{47} \mathrm{~S}_{92}$ & $17 \%$ & $7 \%$ \\
\hline $\mathbf{4}$ & $\mathrm{B}_{205} \mathrm{AA}_{53} \mathrm{~S}_{73}$ & $30 \%$ & $8 \%$ \\
\hline
\end{tabular}


${ }^{a}$ Measured by TGA. ${ }^{b}$ Estimated by the assumption that four AA groups bind one Ti atom and this is the only source of $\mathrm{Ti}$ atom for $\mathrm{TiO}_{2}$.

\section{Conclusion}

Linear and four-arm molecular bottlebrushes with PAA- $b$-PS block copolymer side chains were synthesized and used as templates to prepare hybrid nanoparticles. The shape of nanoparticles was confirmed by TEM, clearly indicating that the molecular templates preserve their dimensions after loading the inorganic content. Despite the different PS blocks, the diameter of worm-like nanoparticles was controlled by the length of PAA segments. This suggests that the boundary of the inorganic core is defined by the interface between the two blocks. Since the PS side chains form a stable shell on the nanoparticle, they provide promising polymeric properties such as processability to the material, indicating some potential applications of the hybrid materials.

\section{Acknowledgements}

Support from the National Science Foundation (via Grants DMR 1501324, DMR 1436219, DMR-1410845, DMR 1122483, DMR 1407645, and DMR 1436201) as well as the Department of Energy (via Grant DE-EE0006702) is acknowledged. JP acknowledges the financial support from National Science Center (via grants DEC- 2012/04/M/ST5/00805, DEC-2011/03/B/ST5/01084, DEC-2014/14/A/ST5/00204).

\section{References}

1. Sheiko SS, Sumerlin BS, and Matyjaszewski K. Progress in Polymer Science 2008;33(7):759-785.

2. Zhang $M$ and Müller AHE. Journal of Polymer Science Part A: Polymer Chemistry 2005;43(16):3461-3481.

3. Yuan J, Müller AHE, Matyjaszewski K, and Sheiko SS. 6.06 - Molecular Brushes. In: Möller KM, editor. Polymer Science: A Comprehensive Reference. Amsterdam: Elsevier, 2012. pp. 199-264.

4. Xia Y, Olsen BD, Kornfield JA, and Grubbs RH. Journal of the American Chemical Society 2009;131(51):18525-18532.

5. Miyake GM, Piunova VA, Weitekamp RA, and Grubbs RH. Angewandte Chemie International Edition 2012;51(45):11246-11248.

6. Miyake GM, Weitekamp RA, Piunova VA, and Grubbs RH. Journal of the American Chemical Society 2012;134(34):14249-14254.

7. Sveinbjörnsson BR, Weitekamp RA, Miyake GM, Xia Y, Atwater HA, and Grubbs RH. Proceedings of the National Academy of Sciences 2012;109(36):14332-14336. 
8. Banquy X, Burdyńska J, Lee DW, Matyjaszewski K, and Israelachvili J. Journal of the American Chemical Society 2014;136(17):6199-6202.

9. Xu H, Sun FC, Shirvanyants DG, Rubinstein M, Shabratov D, Beers KL, Matyjaszewski K, and Sheiko SS. Advanced Materials 2007;19(19):2930-2934.

10. Yamamoto S-i, Pietrasik J, and Matyjaszewski K. Macromolecules 2007;40(26):9348-9353.

11. Yamamoto S-i, Pietrasik J, and Matyjaszewski K. Macromolecules 2008;41(19):7013-7020.

12. Lee H-i, Pietrasik J, Sheiko SS, and Matyjaszewski K. Progress in Polymer Science 2010;35(12):24-44.

13. Nese A, Lebedeva NV, Sherwood G, Averick S, Li Y, Gao H, Peteanu L, Sheiko SS, and Matyjaszewski K. Macromolecules 2011;44(15):5905-5910.

14. Zhang Y, Costantini N, Mierzwa M, Pakula T, Neugebauer D, and Matyjaszewski K. Polymer 2004;45(18):6333-6339.

15. Pakula T, Zhang Y, Matyjaszewski K, Lee H-i, Boerner H, Qin S, and Berry GC. Polymer 2006;47(20):7198-7206.

16. Mpoukouvalas A, Li W, Graf R, Koynov K, and Matyjaszewski K. ACS Macro Letters 2013;2(1):23-26.

17. Daniel WFM, Burdynska J, Vatankhah-Varnoosfaderani M, Matyjaszewski K, Paturej J, Rubinstein M, Dobrynin AV, and Sheiko SS. Nature Materials 2015;advance online publication.

18. Wu D, Nese A, Pietrasik J, Liang Y, He H, Kruk M, Huang L, Kowalewski T, and Matyjaszewski K. ACS Nano 2012;6(7):6208-6214.

19. Bolton J, Bailey TS, and Rzayev J. Nano Letters 2011;11(3):998-1001.

20. Huang K, Jacobs A, and Rzayev J. Biomacromolecules 2011;12(6):2327-2334.

21. Neugebauer D, Zhang Y, Pakula T, and Matyjaszewski K. Macromolecules 2005;38(21):8687-8693.

22. Gao H and Matyjaszewski K. Journal of the American Chemical Society 2007;129(20):6633-6639.

23. Zhao P, Yan Y, Feng X, Liu L, Wang C, and Chen Y. Polymer 2012;53(10):1992-2000.

24. Yan Y, Shi Y, Zhu W, and Chen Y. Polymer 2013;54(21):5634-5642.

25. Beers KL, Gaynor SG, Matyjaszewski K, Sheiko SS, and Möller M. Macromolecules 1998;31(26):9413-9415.

26. Börner HG, Beers K, Matyjaszewski K, Sheiko SS, and Möller M. Macromolecules 2001;34(13):4375-4383.

27. Cheng G, Böker A, Zhang M, Krausch G, and Müller AHE. Macromolecules 2001;34(20):68836888.

28. Matyjaszewski K and Xia J. Chemical Reviews 2001;101(9):2921-2990.

29. Matyjaszewski K and Tsarevsky NV. Journal of the American Chemical Society 2014;136(18):6513-6533.

30. Huang K and Rzayev J. Journal of the American Chemical Society 2009;131(19):6880-6885.

31. Bernard J, Favier A, Davis TP, Barner-Kowollik C, and Stenzel MH. Polymer 2006;47(4):10731080 .

32. Nese A, Kwak Y, Nicolaÿ R, Barrett M, Sheiko SS, and Matyjaszewski K. Macromolecules 2010;43(9):4016-4019.

33. Nese A, Li Y, Averick S, Kwak Y, Konkolewicz D, Sheiko SS, and Matyjaszewski K. ACS Macro Letters 2012;1(1):227-231.

34. Cheng C, Qi K, Khoshdel E, and Wooley KL. Journal of the American Chemical Society 2006;128(21):6808-6809.

35. Börner HG, Duran D, Matyjaszewski K, da Silva M, and Sheiko SS. Macromolecules 2002;35(9):3387-3394.

36. Qin S, Matyjaszewski K, Xu H, and Sheiko SS. Macromolecules 2003;36(3):605-612.

37. Lord SJ, Sheiko SS, LaRue I, Lee H-I, and Matyjaszewski K. Macromolecules 2004;37(11):42354240.

38. Lee H-i, Matyjaszewski K, Yu S, and Sheiko SS. Macromolecules 2005;38(20):8264-8271.

39. Neugebauer D, Theis M, Pakula T, Wegner G, and Matyjaszewski K. Macromolecules 2006;39(2):584-593.

40. Lee H-i, Matyjaszewski K, Yu-Su S, and Sheiko SS. Macromolecules 2008;41(16):6073-6080.

41. Elsen AM, Li Y, Li Q, Sheiko SS, and Matyjaszewski K. Macromolecular Rapid Communications 2014;35(2):133-140. 
42. Boyce JR, Shirvanyants D, Sheiko SS, Ivanov DA, Qin S, Börner H, and Matyjaszewski K. Langmuir 2004;20(14):6005-6011.

43. Lee H-i, Jakubowski W, Matyjaszewski K, Yu S, and Sheiko SS. Macromolecules 2006;39(15):4983-4989.

44. Nese A, Li Y, Sheiko SS, and Matyjaszewski K. ACS Macro Letters 2012;1(8):991-994.

45. Neugebauer D, Zhang Y, Pakula T, Sheiko SS, and Matyjaszewski K. Macromolecules 2003;36(18):6746-6755.

46. Stals PJM, Li Y, Burdyńska J, Nicolaÿ R, Nese A, Palmans ARA, Meijer EW, Matyjaszewski K, and Sheiko SS. Journal of the American Chemical Society 2013;135(31):11421-11424.

47. Djalali R, Li S-Y, and Schmidt M. Macromolecules 2002;35(11):4282-4288.

48. Zhang $M$, Estournès $\mathrm{C}$, Bietsch $\mathrm{W}$, and Müller AHE. Advanced Functional Materials 2004;14(9):871-882.

49. Zhang M, Drechsler M, and Müller AHE. Chemistry of Materials 2004;16(3):537-543.

50. Tang C, Dufour B, Kowalewski T, and Matyjaszewski K. Macromolecules 2007;40(17):6199-6205.

51. Yuan J, Drechsler M, Xu Y, Zhang M, and Müller AHE. Polymer 2008;49(6):1547-1554.

52. Yuan J, Xu Y, Walther A, Bolisetty S, Schumacher M, Schmalz H, Ballauff M, and Muller AHE. Nature Materials 2008;7(9):718-722.

53. Xu Y, Yuan J, and Müller AHE. Polymer 2009;50(25):5933-5939.

54. Yuan J, Lu Y, Schacher F, Lunkenbein T, Weiss S, Schmalz H, and Müller AHE. Chemistry of Materials 2009;21(18):4146-4154.

55. Yuan J and Müller AHE. Polymer 2010;51(18):4015-4036.

56. Xu Y, Yuan J, Fang B, Drechsler M, Müllner M, Bolisetty S, Ballauff M, and Müller AHE. Advanced Functional Materials 2010;20(23):4182-4189.

57. Müllner M, Yuan J, Weiss S, Walther A, Förtsch M, Drechsler M, and Müller AHE. Journal of the American Chemical Society 2010;132(46):16587-16592.

58. Yuan J, Schacher F, Drechsler M, Hanisch A, Lu Y, Ballauff M, and Müller AHE. Chemistry of Materials 2010;22(8):2626-2634.

59. Müllner M, Lunkenbein T, Breu J, Caruso F, and Müller AHE. Chemistry of Materials 2012;24(10):1802-1810.

60. Müllner M, Lunkenbein T, Schieder M, Gröschel AH, Miyajima N, Förtsch M, Breu J, Caruso F, and Müller AHE. Macromolecules 2012;45(17):6981-6988.

61. Thompson KL, Mable CJ, Cockram A, Warren NJ, Cunningham VJ, Jones ER, Verber R, and Armes SP. Soft Matter 2014;10(43):8615-8626.

62. Srivastava $S$ and Kotov NA. Soft Matter 2009;5(6):1146-1156.

63. Long Y-Z, Yu M, Sun B, Gu C-Z, and Fan Z. Chemical Society Reviews 2012;41(12):4560-4580.

64. Liang H-W, Liu J-W, Qian H-S, and Yu S-H. Accounts of Chemical Research 2013;46(7):14501461.

65. Teng $X$ and Yang H. Nano Letters 2005;5(5):885-891.

66. Oschmann B, Tahir MN, Mueller F, Bresser D, Lieberwirth I, Tremel W, Passerini S, and Zentel R. Macromolecular Rapid Communications 2015;36(11):1075-1082.

67. Franchini IR, Cola A, Rizzo A, Mastria R, Persano A, Krahne R, Genovese A, Falqui A, Baranov D, Gigli G, and Manna L. Nanoscale 2010;2(10):2171-2179.

68. Lim J, Borg Lz, Dolezel S, Schmid F, Char K, and Zentel R. Macromolecular Rapid Communications 2014;35(19):1685-1691.

69. Hui CM, Pietrasik J, Schmitt M, Mahoney C, Choi J, Bockstaller MR, and Matyjaszewski K. Chemistry of Materials 2014;26(1):745-762.

70. Matyjaszewski K, Qin S, Boyce JR, Shirvanyants D, and Sheiko SS. Macromolecules 2003;36(6):1843-1849.

71. Burdyńska J, Li Y, Aggarwal AV, Höger S, Sheiko SS, and Matyjaszewski K. Journal of the American Chemical Society 2014;136(36):12762-12770.

72. Pang X, Zhao L, Han W, Xin X, and Lin Z. Nature Nanotechnology 2013;8(6):426-431.

73. Jiang B, Pang X, Li B, and Lin Z. Journal of the American Chemical Society 2015;137(36):1176011767.

74. Yang D, Pang X, He Y, Wang Y, Chen G, Wang W, and Lin Z. Angewandte Chemie 2015;127(41):12259-12264. 
75. Xu H, Pang X, He Y, He M, Jung J, Xia H, and Lin Z. Angewandte Chemie International Edition 2015;54(15):4636-4640.

76. Zheng D, Pang X, Wang M, He Y, Lin C, and Lin Z. Chemistry of Materials 2015;27(15):52715278.

77. Feng C, Pang X, He Y, Chen Y, Zhang G, and Lin Z. Polymer Chemistry 2015;6(29):5190-5197.

78. Pang X, He Y, Jiang B, Iocozzia J, Zhao L, Guo H, Liu J, Akinc M, Bowler N, Tan X, and Lin Z. Nanoscale 2013;5(18):8695-8702.

79. Lu D, Hossain MD, Jia Z, and Monteiro MJ. Macromolecules 2015;48(6):1688-1702.

80. Juhari A, Mosnáček J, Yoon JA, Nese A, Koynov K, Kowalewski T, and Matyjaszewski K. Polymer 2010;51(21):4806-4813.

81. Snijkers F, Cho HY, Nese A, Matyjaszewski K, Pyckhout-Hintzen W, and Vlassopoulos D. Macromolecules 2014;47(15):5347-5356. 
Graphical Abstract:

\section{Control via Brush Template}

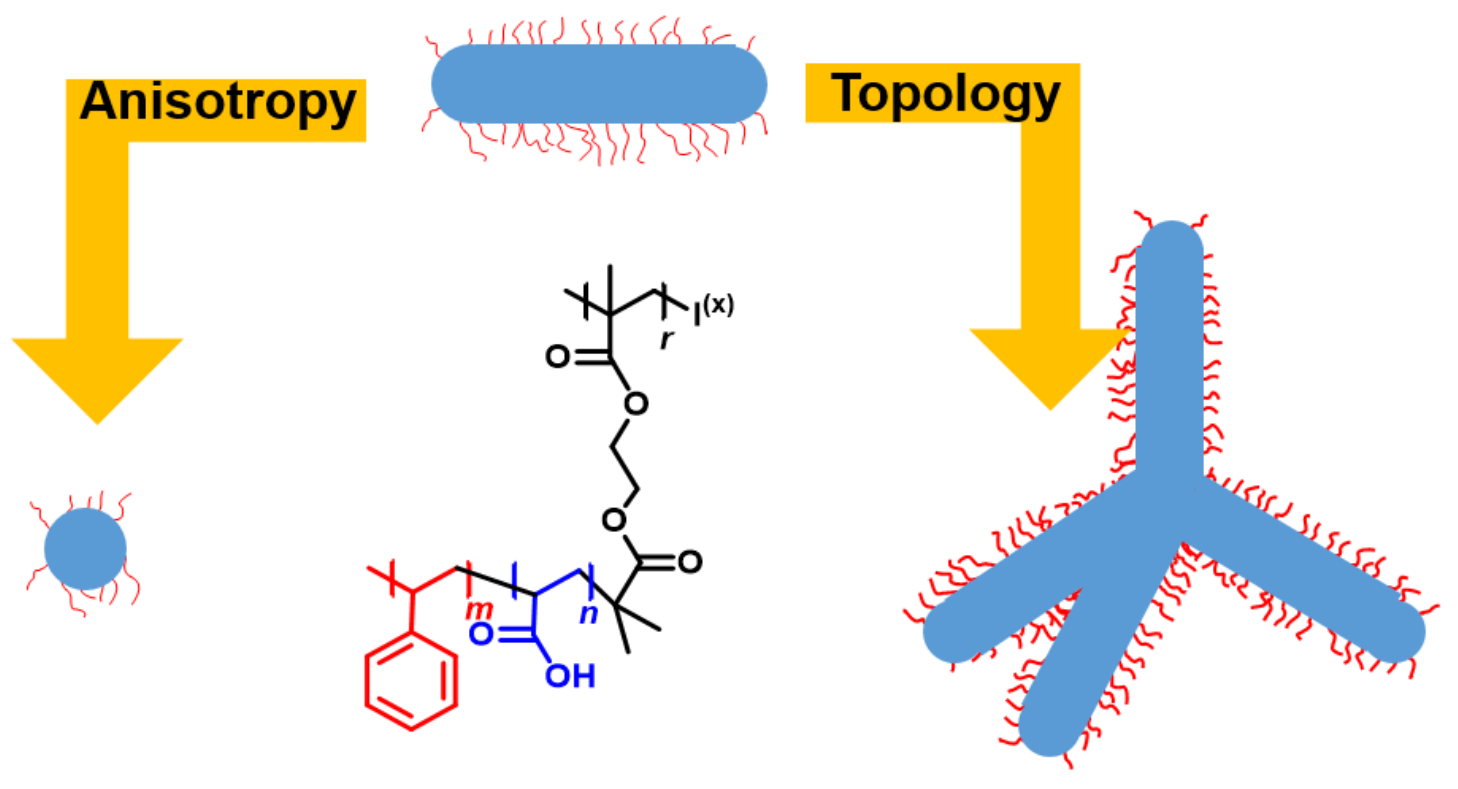

